\title{
Kepuasan Self Monitoring Blood Glucose dengan Kualitas Hidup pada Pasien Diabetes Tipe 2
}

\author{
Shanty Chloranyta ${ }^{1}$, Yulia $^{2}$, Masfuri Sodikin ${ }^{3}$ \\ ${ }^{1}$ Akademi Keperawatan Panca Bhakti, Bandar Lampung, Indonesia \\ ${ }^{2,3}$ Program Studi Magister Keperawatan, Fakultas Ilmu Keperawatan Universitas Indonesia, \\ Depok, Indonesia \\ *Shanty@pancabhakti.ac.id
}

\begin{abstract}
Self monitoring blood glucose (SMBG) is an integral part of diabetes self management. SMBG is effective in improving the quality of life there is a $40.6 \%$ increase in physical and emotional functioning of patients, and $39.13 \%$ confidence. SMBG is not effective in improving the quality of life of patients experiencing frustration, depression and suffering. The purpose of this study was to analyze SMBG satisfaction with quality of life. Cross sectional research design. The population of this study were 51 type 2 diabetes patients with purposive sampling technique. The instruments used were Glucose Monitoring Satisfaction Survey (GMSS), Diabetes Quality of Life Brief (DQoL Brief), Diabetes Self Management Questionnaire (DSMQ). Data analysis used Pearson test. The results showed respondents (78.4\%) were female, (58.8\%) had hypertension complications, (84.3\%) financial support using BPJS, $(62.7 \%)$ using insulin binding 32. The average age of 50.73 years, SMBG satisfaction 49.43, quality of life 49.84, diabetes self management 28. There was a significant relationship between SMBG satisfaction and quality of life $(p=0.000)$. Satisfaction of $S M B G$ improves quality of life in patients with type 2 diabetes.
\end{abstract}

Keyword: type 2 diabetic, self monitoring blood glucose satisfaction, quality of life

\begin{abstract}
Abstrak
Self monitoring blood glucose (SMBG) merupakan bagian integral dari diabetes self management. SMBG efektif dalam dalam meningkatkan kualitas hidup terjadi peningkatan $40.6 \%$ fungsi fisik dan emosional pasien, serta $39.13 \%$ kepercayaan diri. SMBG tidak efektif meningkatkan kualitas hidup pasien mengalami frustasi, depresi dan menderita. Tujuan penelitian ini menganalisis kepuasan SMBG dengan kualitas hidup. Desain penelitian cross sectional. Populasi penelitian ini 51 pasien diabetes tipe 2 dengan teknik purposive sampling. Instrumen yang digunakan Glucose Monitoring Satisfaction Survey (GMSS), Diabetes Quality of Life Brief(DQoL Brief), Diabetes Self Management Questionnaire (DSMQ). Analisis data menggunakan uji pearson. Hasil penelitian didapatkan responden $(78.4 \%)$ berjenis kelamin perempuan, $(58.8 \%)$ mengalami komplikasi hipertensi, $(84.3 \%)$ dukungan pembiayaan menggunakan BPJS, $(62.7 \%)$ menggunakan pengbatan insulin 32. Rerata usia 50.73 tahun, kepuasan SMBG 49.43, kualitas hidup 49.84, diabetes self management 28 . Terdapat hubungan yang signifikan antara kepuasan SMBG dengan kualitas hidup $(\mathrm{p}=0.000)$. Kepuasan SMBG meningkatkan kualitas hidup pada pasien diabetes tipe 2 .
\end{abstract}

Kata kunci: diabetes tipe 2, kepuasan self monitoring blood glucose, kualitas hidup

Jurnal Keperawatan Raflesia, Volume 1 Nomor 2, November 2019

ISSN: (p) 2656-6222 (e) 2657-1595, DOI 10.33088/jkr.vli2.419

Available online: https://jurnal.poltekkes-kemenkes-bengkulu.ac.id/index.php/jkr 


\section{PENDAHULUAN}

Diabetes merupakan masalah kesehatan di dunia. Menurut IDF (2015) prevalensi diabetes akan meningkat $50 \%$ dalam rentang waktu 25 tahun. Peningkatan kasus diabetes pada tahun 2015 sekitar 415 juta dan akan meningkat 642 juta pada tahun 2040. Jumlah kasus diabetes di Indonesia 10 juta pada tahun 2015.

Hiperglikemia kronis akibat diabetes yang tidak ditangani dengan tepat dapat menyebabkan gangguan makrovaskuler dan mikrovaskuler bahkan kematian. Penelitian United Kingdom Prospective Diabetes Study (UKPDS) menunjukkan 5.102 partisipan yang di follow up selama 25 tahun setelah didiagnosa diabetes mengalami komplikasi (Hayes, Leal, Gray, Holman, \& Clarke, 2013).

IDF (2015) merekomendasikan SMBG sebagai bagian integral dari diabetes self management. SMBG efektif untuk meningkatkan kualitas hidup. Hasil penelitian RCT pada 223 pasien, untuk membandingkan penggunaan SMBG pada 113 pasien diabetes dan 110 melakukan pengelolaan diabetes standar dengan perubahan gaya hidup dan diet menunjukkan SMBG signifikan meningkatkan kualitas hidup (Siebolds, Gaedeke, \& Schwedes, 2006).

Penelitian lainnya menunjukkan bahwa SMBG efektif meningkatkan kualitas hidup. Hasil penelitian RCT pada 223 pasien, untuk membandingkan penggunaan SMBG pada 113 pasien diabetes dan 110 melakukan pengelolaan diabetes standar dengan perubahan gaya hidup dan diet menunjukkan SMBG signifikan meningkatkan kualitas hidup (Siebolds, Gaedeke, \& Schwedes, 2006). Penelitian lain yang juga mendukung, membuktikan SMBG signifikan meningkatkan kualitas hidup. SMBG meningkatkan $40.6 \%$ fungsi fisik dan emosional pasien. Kepercayaan diri pasien meningkat $39.13 \%$ terhadap kesehatan setelah follow up selama 6 bulan pada pasien yang melakukan SMBG (Gao et al., 2016).

Kenyataannya SMBG tidak efektif meningkatkan kualitas hidup pasien. Hasil penelitian untuk menilai manfaat SMBG pada kualitas hidup pasien, membuktikan bahwa SMBG memberikan dampak negatif pada kualitas hidup pasien. Analisa penelitian kualitatif meta sintesis pada 7 artikel penelitian, bahwa pasien diabetes mengalami frustasi, depresi dan merasa bahwa prosedur pengukuran glukosa darah membuat pasien merasa menderita karena harus terus menerus mengukur kadar glukosa darah secara rutin (Chen \& Yeh, 2014: Fisher, 2007).

\section{METODE}

Penelitian ini merupakan penelitian kuantitatif dengan desain deskriptif analitik menggunakan pendekatan cross sectional. Tujuan penelitian untuk menganalisis kepuasan SMBG dengan kualitas hidup pada pasien diabetes tipe 2. Responden dalam penelitian ini berjumlah 51 orang dengan diabetes tipe 2 di Poliklinik Penyakit Dalam RS Abdul Muluk dan Persadia Bandar Lampung. Kriteria inklusi yakni pasien diabetes tipe 2 ditunjukkan dengan rekam 
medis pasien, didapatkan dari informasi dokter spesialis penyakit dalam dan perawat poliklinik RSAM Bandar Lampung, dapat berkomunikasi dengan baik, mampu membaca dan menulis dengan bahasa Indonesia, bersedia menjadi responden dalam penelitian ini. Sedangkan kriteria eksklusi dalam penelitian ini mengalami cacat fisik (tunanetra, tunadaksa), dan mengalami depresi dibuktikan dengan screening untuk mengukur depresi dengan menggunakan instrument CES-D.

Penelitian ini dilakukan dari bulan FebruariMaret 2017. Lokasi penelitian adalah RSAM dan Persadia Bandar Lampung. Data diambil dengan menggunakan alat ukur Glucose Monitoring Satisfaction Survey (GMSS), Diabetes Quality of Life Brief (DQoL Brief), Diabetes Self Management Questionnaire (DSMQ), Center for Epidemiologic Studies Depression Scale (CES-D).

Uji instrumen dilakukan pada 30 pasien diabetes di poliklinik RSAM Provinsi Lampung Uji dengan menggunakan validitas rupa dan validitas konstruk. Hasil uji validitas terhadap kuesioner GMSS menggunakan korelasi Pearson Product Moment menyatakan 15 item pernyataan valid dengan keseluruhan nilai $r>0,361$ dan uji reliabilitas didapatkan nilai cronbach- $\alpha$ 0,942 sehingga kuesioner dinyatakan reliabel.

Hasil uji validitas kuesioner DQoL Brief dengan menggunakan korelasi Pearson
Product Moment pada 15 item pernyataan menyatakan bahwa nilai untuk setiap item pernyataan $>$ r tabel $(0,361)$ sehingga seluruh item pernyataan dinyatakan valid. Hasil uji reliabilitas didapatkan nilai cronbach- $\alpha$ 0,917 sehingga kuesioner dinyatakan reliabel.

Hasil uji validitas kuesioner CES-D diuji menggunakan korelasi Pearson Product Moment pada 20 pernyataan depresi menyatakan bahwa pernyataan nomor 8 tidak valid karena nilai < r tabel $(0,361)$. Namun, dengan pertimbangan bahwa item nomor 8 konten yang perlu diketahui dalam melihat depresi sehingga peneliti melakukan perubahan pada kalimat dan item tersebut tetap dimasukkan dalam kuesioner. Hasil uji reliabilitas terhadap 19 item pernyataan didapatkan hasil cronbach- $\alpha$ 0,888 sehingga kuesioner dinyatakan reliabel.

Hasil uji kuesioner DSMQ menggunakan korelasi Pearson Product Moment pada 16 pernyataan menyatakan bahwa pernyataan nomor 8 dan nomor 13 tidak valid karena nilai < $\mathrm{r}$ tabel (0.361). Namun, dengan pertimbangan bahwa item nomor 8 dan 13 konten yang perlu diketahui sehingga item tersebut tetap dimasukkan dalam kuesioner. Hasil uji reliabilitas terhadap 16 item pernyataan didapatkan hasil cronbach- $\alpha$ 0,939 sehingga kuesioner dinyatakan reliabel. 


\section{HASIL}

Tabel 1. Distribusi Responden Berdasarkan Jenis Kelamin, Komplikasi, Dukungan Pembiayaan, Pengobatan di RSAM dan Persadia Bandar Lampung Tahun 2017

\begin{tabular}{lcc}
\hline \multicolumn{1}{c}{ Kategori } & $\mathrm{n}$ & $(\%)$ \\
\hline Jenis Kelamin & & \\
$\quad$ Laki-laki & 11 & 21.6 \\
$\quad$ Perempuan & 40 & 78.4 \\
Komplikasi & 21 & 41.2 \\
$\quad$ Tidak ada & 30 & 58.8 \\
$\quad$ Hipertensi & 0 & 0 \\
Retinopati Diabetik & 0 & 0 \\
Gagal Ginjal Kronis (GGK) & 0 & 0 \\
$\quad$ Ulkus Diabetik & 0 & 0 \\
$\quad$ Penyakit Jantung Koroner & 0 & 0 \\
Stroke & & \\
& & \\
Dukungan Pembiayaan & 43 & 84.3 \\
$\quad$ BPJS & 8 & 15.7 \\
$\quad$ Asuransi Kesehatan Swasta & 0 & 0 \\
$\quad$ Pribadi (Out of Pocket) & & \\
Pengobatan & 19 & 37.3 \\
$\quad$ OHO & 32 & 62.7 \\
$\quad$ Insulin & &
\end{tabular}

Tabel 1 menunjukkan karakteristik hipertensi 30 responden $(58.8 \%)$, dukungan responden berdasarkan jenis kelamin pembiayaan terbanyak menggunakan BPJS menunjukkan persentase terbanyak dengan 43 responden $(84.3 \%)$. Pengobatan yang jenis kelamin perempuan sebanyak 40 didapatkan oleh responden terbanyak responden $(78.4 \%)$. Komplikasi terbanyak menggunakan insulin 32 responden $(62.7 \%)$.

Tabel 2. Distribusi Responden Berdasarkan Usia, Kepuasan SMBG, Diabetes Outcome, Kualitas Hidup, Diabetes Self Management Pasien Diabetes Tipe 2 Di RSAM dan Persadia Bandar Lampung Tahun 2017

\begin{tabular}{lcccc}
\hline \multicolumn{1}{c}{ Variabel } & Mean \pm SD & Median & Min-Maks & $95 \%$ CI \\
\hline Usia & $50.73 \pm 3.47$ & 51 & $45-58$ & $49.75-51.70$ \\
Kepuasan SMBG & $49.43 \pm 6.62$ & 50 & $35-65$ & $47.57-51.29$ \\
Kualitas hidup & $49.84 \pm 6.58$ & 51 & $38-68$ & $47.99-51.69$ \\
Diabetes Self Management & $29.63 \pm 4.04$ & 28 & $25-41$ & $28.49-30.77$ \\
\hline
\end{tabular}


Tabel 2. menunjukkan bahwa rerata usia responden diabetes tipe 2 adalah 50.73 tahun dan standar deviasi 3.47. Selain itu, diyakini 95\% rata-rata usia responden berada antara 49.75 tahun hingga 51.70 tahun. Kepuasan SMBG menunjukkan rerata 49.43 dengan standar deviasi 6.62, Selain itu juga diyakini 95\% rerata kepuasan SMBG antara 47.57 hingga 51.29. Kualitas hidup menunjukkan rerata 49.84 dengan standar deviasi 6.58, selain itu juga diyakini $95 \%$ rerata berada antara 47.99 hingga 51.69. Diabetes self management menunjukkan median 28 dengan skor terendah diabetes self management 25 dan tertinggi 41. Selain itu juga diyakini $95 \%$ rata-rata total skor diabetes self management berada antara 28.49 hingga 30.77 .

Tabel 3. Analisis hubungan kepuasan SMBG dengan kualitas hidup pada pasien diabetes tipe 2 di RSAM dan Persadia Bandar Lampung Tahun 2017

\begin{tabular}{lcc}
\hline & \multicolumn{2}{c}{ Kepuasan SMBG } \\
\hline Kualitas Hidup & $\mathrm{p}$ & $0.000^{*}$ \\
\hline
\end{tabular}

*signifikan pada $\mathrm{p}<0.05$

Tabel 3 menunjukkan bahwa hasil uji analisis hubungan kepuasan SMBG dengan kualitas hidup terdapat hubungan yang signifikan ( $\mathrm{p}$ value $<0.000, \alpha 0.05)$.

\section{PEMBAHASAN}

Berdasarkan hasil penelitian analisis kepuasan SMBG dengan kualitas hidup pada pasien diabetes di RSAM dan Persadia Bandar Lampung memberikan gambaran sebagai berikut:

\section{Karakteristik Pasien Diabetes Tipe 2}

Hasil penelitian ini menunjukkan bahwa kemungkinan kejadian diabetes dalam penelitian ini disebabkan karena perubahan metabolisme pada tubuh diakibatkan oleh proses penuaan. Selain itu, gangguan pada tubuh akibat proses penuaan yakni kelemahan dapat menyebabkan berkurangnya mobilitas sehingga terjadi pengurangan pengeluaran energi dan insulin. Penuaan dikaitkan dengan hilangnya fungsi mitokondria secara progresif dalam berbagai bentuk jaringan, termasuk otot rangka (Barzilai et al., 2012).

Demikian halnya dengan penelitian prospective cohort study untuk mengidentifikasi faktor resiko onset terjadinya diabetes menunjukkan dari 2.459 subjek penelitian dan 144 subjek penelitian yang mengalami diabetes berusia pada rentang 18-50 tahun, dan insidensi kejadian diabetes pada usia 40-50 tahun yaitu 3.4\% per 1000 orang dalam setiap tahunnya. Peningkatan kejadian diabetes $8.6 \%$ pada usia 40-50 tahun dan 7.7\% meningkat pada usia 30-39 tahun (Nguyen et al., 2012). Kejadian diabetes di Indonesia berdasarkan data Riskesdas (2013) menunjukkan pada rentang usia 45-55 tahun (3.3\%), 55-64 tahun (4.8\%), 65-74 tahun (4.2\%).

Perempuan dalam penelitian ini merupakan responden terbanyak dengan rerata usia 50.73 tahun karena sampel dalam penelitian ini lebih banyak perempuan, selain itu kemungkinan dapat disebabkan oleh perubahan hormonal yang terjadi akibat proses penuaan sehingga mengakibatkan 
resiko lebih tinggi terjadi diabetes pada perempuan dibandingkan dengan laki-laki. Selain itu, faktor resiko yang berkontribusi pada perempuan dengan diabetes tipe 2 yakni perempuan memiliki BMI lebih tinggi dibandingkan dengan laki-laki. Hasil penelitian yang dilakukan oleh The Korea National Health and Nutrition Examination Survey sejak tahun 2007 sampai dengan 2010 pada 21.797 responden menunjukkan rerata body mass index (BMI) $26.1 \mathrm{~kg} / \mathrm{m}^{2}$ pada perempuan dan $25.0 \mathrm{~kg} / \mathrm{m}^{2}$ pda laki-laki (Kwon, 2014).

Berdasarkan beberapa penelitian menunjukkan prevalensi diabetes lebih tinggi pada perempuan dibandingkan dengan lakilaki, seperti pada penelitian cross sectional untuk menentukan prevalensi jenis kelamin dan usia yang berhubungan dengan faktor resiko diabetes di Nigeria. Hasil penelitian yang dilakukan pada 3.500 responden menunjukkan kejadian diabetes pada responden perempuan 1.968 (56.2\%) lebih banyak dibandingkan pada laki-laki yaitu 1.532 (43.8 \%) (Ekpenyong, Akpan, Ibu, \& Nyebuk, 2012).

Berbeda halnya dengan penelitian prevalensi diabetes menurut data IDF (2015) berdasarkan jenis kelamin prevalensi diabetes lebih tinggi pada laki-laki dibandingkan dengan perempuan. Kelompok usia 40-49 tahun pada laki-laki lebih tinggi kejadian diabetes $11 \%$ dibandingkan perempuan yakni $8 \%$, dan usia 50-59 tahun diabetes laki-laki sekitar $16 \%$ dan perempuan yakni $13 \%$. Demikian halnya dengan penelitian cross sectional yang dilakukan di China dengan 1.545 pasien diabetes tipe 2 menunjukkan kejadian diabetes pada laki-laki $67.81 \%$ dan $32.2 \%$ perempuan (Yu et al., 2016).

Hipertensi merupakan komplikasi terbanyak berdasarkan hasil analisis Resiko penyakit kardiovaskuler (CVD) pada diabetes diakibatkan oleh multifaktor yang kompleks. Selain itu, ditemukan kelainan struktur partikel lipoprotein pada plasma pasien dengan diabetes. Pada diabetes bentuk dominan dari LDL kecil dan padat. Partikel LDL yang kecil lebih aterogenik dari partikel LDL yang besar, karena dapat lebih mudah menembus dan membentuk lapisan kuat pada dinding arteri dan mudah teroksidasi. LDL yang teroksidasi merupakan proaterogenik, dan mengakibatkan perubahan, meliputi menarik leukosit ke intima, meningkatkan kemampuan leukosit untuk menelan lipid dan berdiferensiasi menjadi sel busa, dan merangsang proliferasi leukosit, endotel sel, dan sel-sel otot polos, sehingga terbentuk formasi plak aterosklerotik (Dokken, 2008).

Hasil analisis menunjukkan dukungan pembiayaan terbanyak menggunakan BPJS Umumnya responden dalam penelitian ini menggunakan BPJS kesehatan karena rerata responden merupakan pegawai Negeri Sipil. BPJS memiliki 2 jenis produk yakni BPJS ketenagakerjaan dan BPJS kesehatan. BPJS Kesehatan diperuntukkan asuransi kesehatan, sebagai proteksi nasabah saat terjadi masalah kesehatan karena kecelakaan atau sakit dan harus melakukan upaya pengobatan, sedangkan BPJS ketenagakerjaan meliputi investasi yang menjadi tabungan dana pensiun dan asuransi kecelakaan yang banyak diperuntukkan bagi karyawan swasta. 
Berdasarkan beberapa penelitian yang juga menunjukkan umumnya pasien diabetes menggunakan asuransi kesehatan, seperti pada penelitian dengan 1.079 responden penelitian menunjukkan pasien dengan diabetes yang menggunakan asuransi kesehatan 900 pasien $(92.0 \%$ ) dan pasien yang tidak menggunakan asuransi kesehatan atau pribadi yakni 78 pasien (8\%) (Al-keilani et al., 2017).

Hasil analisis menunjukkan $62.7 \%$ responden menggunakan insulin. Penggunaan insulin pada pasien diabetes dapat mengurangi resiko komplikasi pada diabetes yakni kematian (RR: 0.92, 95\% CI: 0.80-1.07), infark miokard (RR:1.07, 95\% CI: 0,90), stroke (RR:. 0.88, 95\% CI: 0,591,32) serta amputasi (RR: 0.92, 95\% CI: 0,48-1,74), kebutaan (RR: 1.10, 95\% CI:. 0.76-1.60) atau gagal ginjal (RR: 0.68, 95\% CI: 0.43-1.06) (Erpeldinger et al., 2016).

Penelitian menunjukkan penggunaaan $\mathrm{OHO}$ efektif pada pasien diabetes, serta tidak menyebabkan hipoglikemia dibandingkan dengan insulin. Hasil penelitian meta analisis random control trial pada 1.632 artikel penelitian dan 18.599 sampel membuktikan obat hipoglikemia oral dibandingkan dengan insulin secara signifikan lebih rendah terjadinya resiko hipoglikemia (RR: 2.62 95\% CI:2.48-2.77) (Erpeldinger et al., 2016).

Pemberdayaaan dan persiapan pasien untuk mengelola kesehatan dan perawatan kesehatan dengan menekankan peran sentral pasien dalam mengelola kesehatan, menggunakan strategi dukungan manajemen mandiri yang efektif yang mencakup penilaian, penetapan tujuan, perencanaan tindakan, pemecahan masalah dan tindak lanjut serta mengatur sumber daya internal dan masyarakat untuk memberikan dukungan manajemen mandiri kepada pasien. (Stellefson, Dipnarine, \& Stopka, 2013).

Hasil penelitian menunjukkan rerata responden dalam penelitian ini dengan rerata total skor 49.43 dari total skor tertinggi kepuasan SMBG 75. Hal ini menunjukkan 65 $\%$ responden dalam penelitian ini memiliki total skor 49.43 dari 51 responden. Kepuasan yang dimaksud dalam penelitian ini menggambarkan harapan pasien setelah melakukan self monitoring blood glucose meliputi keterbukaan, pengaruh emosional, perilaku dan manfaat dari monitoring glukosa darah yang diukur dengan menggunakan alat ukur GMSS (Polonsky et al., 2015). Hasil penelitian ini sesuai oleh penelitian yang dilakukan di UK pada pasien diabetes type 2 yang melakukan SMBG pada 554 responden diabetes tipe 2 menunjukkan $80 \%$ responden melaporkan kepuasan dalam melakukan SMBG. Responden menyatakan merasa diabetes dapat terkontrol dengan melakukan SMBG (Barnard, Young, \& Waugh, 2010).

Hasil penelitian menunjukkan rerata responden dalam penelitian ini dengan rerata total skor 49.84 dari total skor tertinggi kualitas hidup 75. Hal ini menunjukkan 66.5 $\%$ responden dalam penelitian ini memiliki total skor 49.84 dari 51 responden. Kualitas hidup dalam penelitian ini menggambarkan ungkapan perasaan pasien terhadap kepuasan, dampak terhadap pengelolaan diabetes, kecemasan akibat diabetes, dan hubungan sosial. (Huang et al., 2008; 
Burroughs, Desikan, Waterman, Gilin, \& Mcgill, 2004).

Hasil penelitian ini menunjukkan dari item pertanyaan yang diukur skor kepuasan terhadap treatment memiliki nilai tertinggi dibandingkan dengan skor nilai dari pengaruh negatif dari diabetes. Hal ini menunjukkan responden dalam penelitian ini memiliki kepuasan dalam melakukan SMBG sehingga responden memiliki kualitas hidup yang baik dan diabetes outcome sesuai dengan target yang ingin dicapai membuat pasien merasa puas.

Penelitian yang dilakukan pada 2.135 pasien membuktikan kompleksitas pengobatan pada diabetes, komplikasi akibat hiperglikemia kronis serta perubahan gaya hidup yang harus dilakukan pasien untuk menjaga diabetes outcome memberikan dampak pada kualitas hidup pasien (Saito et al., 2006). Selain itu, diabetes memberikan pengaruh terhadap kondisi fisik pada orang diabetes. Hasil penelitian cohort tentang kualitas hidup dan mortalitas pada 1.353 pasien diabetes tipe 2 yang di follow up 9.6 tahun membuktikan bahwa diabetes menyebabkan masalah fisik. Perubahan fisik yang terjadi pada pasien diabetes yaitu $42 \%$ pasien meninggal, dan kematian yang diakibatkan oleh penyakit kardiovaskuler $49 \%$. Hasil analisa diabetes meningkatkan resiko penyakit kardiovaskuler sehingga pasien merasa cemas dan mempengaruhi kualitas hidup (Landman et al., 2010).

Diabetes juga mempengaruhi tingkat ketergantungan pasien dengan orang lain. Penelitian cross sectional pada 2.403 sampel, terdiri dari 839 pasien diabetes dan 1.564 non diabetes membuktikan bahwa diabetes memberikan dampak negatif. Pasien dengan diabetes membutuhkan bantuan orang lain dalam memenuhi kebutuhan sehari-hari dan mobilitas setelah menderita diabetes 8-15 tahun. Selain itu, pasien yang baru didagnosis diabetes juga mengalami dampak negatif pada kualitas hidup karena pasien mengalami perubahan dalam kehidupan serta membutuhkan waktu dalam meyesuaikan diri terhadap pengelolan diabetes (Sparring et al., 2013).

\section{Hubungan antara kepuasan SMBG dengan kualitas hidup}

Hasil uji statistik dalam penelitian ini menunjukkan bahwa terdapat hubungan yang signifikan antara kepuasan SMBG dengan kualitas hidup dengan $p$ value $<0.05$. Kepuasan SMBG yang dimaksud dalam penelitian ini adalah kepuasan responden dalam melakukan SMBG yang dilihat dari alat ukur GMSS. SMBG memberikan dampak yang besar dalam kualitas hidup pasien diabetes. Hasil penelitian yang mendukung, membuktikan SMBG signifikan meningkatkan kualitas hidup. SMBG meningkatkan $40.6 \%$ fungsi fisik dan emosional pasien. Kepercayaan diri pasien meningkat $39.13 \%$ terhadap kesehatan setelah follow up selama 6 bulan pada pasien yang melakukan SMBG (Gao et al., 2016).

Berbeda halnya dengan penelitian PRISMA study yang dilakukan untuk mengevaluasi pemantauan diri secara terstruktur terhadap SMBG dengan perubahan kualitas hidup spesifik diabetes dan locus of control (LOC) 
pada pasien 1.024 pasien diabetes tipe 2 yang tidak menggunakan insulin dan dilakukan follow up selama 12 bulan. Hasil penelitian menunjukkan tidak terdapat perbedaan yang signifikan antara kepuasan SMBG dan kualitas hidup baik pada kelompok kontrol dan kelompok intervensi (Russo et al., 2016).

Demikian halnya dengan penelitian kualitatif meta sintesis SMBG tidak efektif meningkatkan kualitas hidup pasien. Hasil penelitian untuk menilai manfaat SMBG pada kualitas hidup pasien, membuktikan bahwa SMBG memberikan dampak negatif pada kualitas hidup pasien. Hasil analisis pasien diabetes mengalami frustasi, depresi dan merasa bahwa prosedur pengukuran glukosa darah membuat pasien merasa menderita karena harus terus menerus mengukur kadar glukosa darah secara rutin (Chen \& Yeh, 2014: Fisher, 2007). Kualitas hidup pada pasien diabetes tipe 2 dipengaruhi oleh kepuasan. Kepuasan merupakan indikator yang digunakan untuk mengevaluasi perspektif pasien dan memberikan gambaran mengenai harapan dan preferensi pasien pada komponen dari proses perawatan (Doubova et al., 2009).

Hasil penelitian kualitatif untuk menjelaskan persepsi dan fungsi SMBG pada orang diabetes tipe 2. Pasien akan melakukan SMBG apabila merasa puas dapat mencapai kadar glukosa darah sesuai dengan target yang ditentukan. (Brackney, 2010). Demikian halnya, penelitian cross sectional yang dilakukan pada 6.671 pasien diabetes di Brazil menunjukkan bahwa pasien yang puas terhadap hasil pengelolaan diabetes memiliki diabetes outcome yang adekuat (Mendez et al., 2010).

Pengelolaan diabetes dalam waktu lama dan terus menerus membutuhkan kebulatan tekad dan keyakinan pasien. Keyakinan menjadi komponen penting dan utama dalam menentukan keberhasilan terapi. Perubahan perilaku dapat terjadi apabila individu berhasil mengatasi hambatan yang dirasakan, merasakan manfaat, self efficacy, dan mengatasi ancaman (Jones et al., 2015). Keyakinan self efficacy memberikan gambaran mengenai kepercayaan diri terhadap tingkah laku yang disarankan (Gherman et al., 2011).

Self efficacy mengarahkan pada penilaian individu akan kemampuannya. Individu dengan self efficacy yang tinggi akan lebih gigih, terus berusaha dan berupaya dalam mencapai tujuan. Kemampuan seorang individu dalam melakukan suatu tugas tidak serta merta dapat meningkatkan self efficacy, namun dipengaruhi juga oleh kesuksesan dan kegagalan yang dialami, persepsi terhadap tingkat kesulitan, usaha yang dilakukan dalam mencapai tujuan, pengalaman yang diingat dan diproses oleh daya ingat serta adanya bantuan eksternal dari lingkungan.

\section{KESIMPULAN}

Hasil uji statistik menunjukkan terdapat hubungan yang signifikan antara kepuasan SMBG dengan kualitas hidup. Perlunya meningkatkan proses keperawatan khususnya pengkajian untuk mengetahui 
kualitas hidup pasien diabetes tipe 2 sehingga dapat meningkatkan kemampuan pasien dalam melakukan SMBG.

\section{DAFTAR PUSTAKA}

Al-keilani, M. S., et al. (2017). Self monitoring of blood glucose among patients with diabetes in Jordan: Perception, adherence, and influential factors. Diabetes Research and Clinical Practice. http://doi.org/10.1016/j.diabres.2017.01.00 5.

Barnard, K. D., Young, A. J., \& Waugh, N. R. (2010). Self monitoring of blood glucose a survey of diabetes UK members with type 2 diabetes who use SMBG. BMC Research Notes, 3(1), 318.

Barzilai, N., et al. (2012). The critical role of metabolic pathways in aging. Diabetes, 61, 1315-1322.

Brackney, D. E. (2010). "Knowing where i am at ": The experience of self monitoring blood glucose for people with non insulin requiring type 2 diabetes.

Burroughs, T. E., Desikan, R., Waterman, B. M., Gilin, D., \& Mcgill, J. (2004). Development and validation of the diabetes quality of life brief clinical inventory. Diabetes Spectrum, 17(1), 41-49.

Chen, C., \& Yeh, M. C. (2014). The experiences of diabetics on self-monitoring of blood glucose: A qualitative metasynthesis. Journal of Clinical Nursing, 24(1), 614626. http://doi.org/10.1111/jocn.12691.

Dokken, B. B. (2008). The pathophysiology of cardiovascular disease and diabetes: beyond blood pressure and lipids. Diabetes Research and Clinical Practice, 21(3), 160165.

Doubova, S. V., et al. (2009). Satisfaction of patients suffering from type 2 diabetes and / or hypertension with care offered in family medicine clinics in Mexico, 51(3), 231219.

Ekpenyong, C. E., Akpan, U. P., Ibu, J. O., \& Nyebuk, D. E. (2012). Gender and age specific prevalence and associated risk factors of type 2 diabetes mellitus in Uyo Metropolis South Eastern Nigeria. Diabetologia Croatica, 17-28.

Erpeldinger, S., et al. (2016). Efficacy and safety of insulin in type 2 diabetes : Meta-analysis of randomised controlled trials. Journal BMC Endocrine Disorders, 16, 1-15.

Fisher, W. A. (2007). Barriers and behaviors in blood glucose monitoring, (1992), 51-53.

Gao, L., et al. (2016). Impact of structured selfmonitoring of blood glucose on the quality of life of insulin-treated chinese patients with type 2 diabetes mellitus: Results from the COMPASS study. Diabetes Research and Clinical Practice, 2(112), 88-93.

Gherman, et al. (2011). How are adherent people more likely to think? The Diabetes Educator, 37(3), 392-408. http://doi.org/10.1177/0145721711403012

Hayes, A. J., Leal, J., Gray, A. M., Holman, R. R., \& Clarke, P. M. (2013). UKPDS outcomes model 2: A new version of a model to simulate lifetime health outcomes of patients with type 2 diabetes mellitus using data from the 30 year United Kingdom Prospective Diabetes Study: UKPDS 82 Lipids in Diabetes Study. Diabetologia, 56, 1925-1933.

Huang, E., et al. (2008). Patient perceptions of quality of life with diabetes related complications and treatments. Diabetes and Metabolism Journal, 30(10), 2478-2483.

International Diabetes Federation. (2015). IDF diabetes atlas $7^{\text {th }}$ edition 2015 . https://www.idf.org/elibrary/epidemiology-research/diabetes- 
atlas/13-diabetes-atlas-seventhedition.html.

Jones, C. L., et al. (2015). The health belief model as an explanatory framework in communication research: Exploring parallel, serial, and moderated mediation. Health Communication, 30(6), 566-576.

Kwon, S. K. (2014). Women are diagnosed with type 2 diabetes at higher body mass indices and older ages than men: Korea National Health and Nutrition Examination Survey. Diabetes and Metabolism Journal, 38, 7480.

Landman, G. W., et al. (2010). Health related quality of life and mortality in a general and elderly population of patients with type 2 diabetes. Journal Diabetes Care, 33(11), 2378-2382. http://doi.org/10.2337/dc100979 .

Mendez, A. B. V.,et al. (2010). Prevalence and correlates of inadequate glycaemic control : results from a nationwide survey in 6671 adults with diabetes in Brazil. Jounal Acta Diabetol, 47, 137-145.

Nguyen, Q. M., et al. (2012). Correlates of Age Onset of Type 2 Diabetes Among Relatively Young Black and White Adults in a Community. Diabetes Care, 35, 13411346 .

Polonsky, W. H., et al. (2015). Development of a new measure for assessing glucose monitoring device related treatment satisfaction and quality of life. Diabetes Technology \& Therapeutics, 17(9), 657663. http://doi.org/10.1089/dia.2014.0417

Russo, et al. (2016). The burden of structured self monitoring of blood glucose on diabetes specific quality of life and locus of Control. Diabetes Te, 18(7), 421-428. http://doi.org/10.1089/dia.2015.0358.

\footnotetext{
Riskesdas. (2013). Riset kesehatan dasar RISKESDAS 2013. Diunduh dari https://wwwdepkes.go.id.
}

Saito, I., et al. (2006). Impact of diabetes on health-related quality of life in a population study in japan. Diabetes Research and Clinical Practice, 73, 51-57. http://doi.org/10.1016/j.diabres.2005.11.01 5.

Sparring, V., et al. (2013). Diabetes duration and health-related quality of life in individuals with onset of diabetes in the age group 15 - 34 years - a Swedish population- based study using EQ-5D. Journal BMC Public Health, 13(377). http://doi.org/10.1186/147-2458-13-377

Siebolds, M., Gaedeke, O., \& Schwedes, U. (2006). Self-monitoring of blood glucose Psychological aspects relevant to changes in HbA $1 \mathrm{c}$ in type 2 diabetic patients treated with diet or diet plus oral antidiabetic medication, 62, 104-110.

Stellefson, M., Dipnarine, K., \& Stopka, C. (2013). The chronic care model and diabetes management in us primary care settings: A systematic review. Centers for Disease Control and Prevention, 10(1), 121.

Yu, H., et al. (2016). Initiating characteristics of early-onset type 2 diabetes mellitus in chinese patients. Chinese Medical Journal, 129(7), 1-7. http://doi.org/10.4103/03666999.178959. 
98 | Jurnal Keperawatan Raflesia, Volume 1 Nomor 2, November 2019

\section{HALAMAN INI SENGAJA DI KOSONGKAN}

